\title{
FATIGUE (FEA) AND MODAL ANALYSIS OF A CENTRIFUGAL FAN
}

\author{
Manish Dadhich ${ }^{1,}$ Sheetal Kumar Jain ${ }^{2}$, Vikas Sharma ${ }^{1}$, Sanjay Kumar Sharma ${ }^{1}$, \\ Dhirendra Agarwal ${ }^{3}$ \\ 'Grob Design Pvt. Ltd., Jaipur, Rajasthan, India \\ ${ }^{2}$ Apex Institute Of Engineering and Technology, Jaipur, Rajasthan, India \\ ${ }^{3}$ FET Agra College, Agra ,Uttar Pradesh,India
}

\begin{abstract}
:
Centrifugal fans are high speed rotating turbo machines vulnerable to vibrations resulting in the failure of the system eventually. During every start-up and shutdown of centrifugal fan, the fan blades are subjected to centrifugal, bending and vibratory loads. This repeated start-up and shutdown can reduce the life of fan blades. A fatigue and modal analysis of the fan is, therefore, very important in the design and development of fans, to prevent premature failure. In this paper the finite element analysis of a centrifugal fan impeller, for a high tuned design is carried out using ANSYS. The Finite Element Analysis is to be done on the following platform, "Fatigue and modal analysis at $705 \mathrm{rpm}$ at $110^{\circ} \mathrm{F}$ " to determine the various performance parameters. Analysis is linear static structural and the model used is Gerber stress theory. From fatigue analysis we can determine whether the fan is safe to run in the operating conditions and further the design can be improved. Modal analysis of the fan is very important in the design and development of fan, to prevent premature failure. In modal analysis the first ten natural frequencies were compared to the frequency generated from fan operating speed. This is done to avoid resonance phenomenon which causes the vibration failure. So that fan can run safely in the operating conditions.
\end{abstract}

\section{Keywords:}

ANSYS, Centrifugal fan, Fatigue analysis, Finite element analysis, Gerber stress theory, Modal analysis and Resonance.

\section{Introduction}

A centrifugal fan is a mechanical device for moving air or other gases. These fans increase the speed of air stream with the rotating impellers. They use the kinetic energy of the impellers or the rotating blade to increase the pressure of the air/gas. The centrifugal fan is one of the most widely used fans. Centrifugal fans are by far the most prevalent type of fan used in the Heat Ventilation and Air Conditioning industry today. They are usually cheaper than axial fans and simpler in construction. In automotive industries, fans are used for cooling internal combustion engines. They are also used commonly in central heating/cooling systems.

\subsection{Working Principle:}

The centrifugal fan uses the centrifugal power generated from the rotation of impellers to increase the pressure of air/gases. When the impellers rotate, the gas near the impellers is thrown-off from the impellers due to the centrifugal force and then moves into the fan casing. As a result the gas pressure in the fan casing is increased. The gas is then guided to the exit via outlet ducts. After the gas is thrown-off, the gas pressure in the middle region of the impellers decreases. The gas from the impeller eye rushes in to normalize this pressure. This cycle repeats and therefore the gas can be continuously transferred. 


\subsection{Finite Element Analysis:}

Finite Element Analysis (FEA) is a numerical technique that can be used to approximate the structural dynamic characteristics of vibrating mechanical systems, the understanding of which is paramount to any root-cause failure study involving excessive vibrations. The Finite Element technique can be used for structural dynamic studies of existing equipment or to evaluate the dynamic characteristics of machines and structures prior to fabrication. The finite element method is a numerical technique that can be used to approximate the modal parameters (natural frequencies and mode shapes) of complex structural-mechanical systems.

\subsection{Present Work:}

This paper concentrate exclusively on the Finite element (FE) modelling of the impeller of the centrifugal fan; special emphasis will be given to how rational analysis of many aspects affecting the failure can interact with FE to rule out any unlikely possibilities. FE is used mainly to eliminate resonance of impeller of centrifugal fan and evaluate equivalent stress concentration and total deformation on the impeller of centrifugal fan.

The purpose of the present study is to show the fatigue analysis (FEA) and modal analysis of a centrifugal fan using the commercial software's like Catia (V5R20) and ANSYS 12. In the present work the fatigue (FEA) analysis is carried out to check the total deformation and equivalent stress on the impeller of the centrifugal fan and further the modal analysis was done to avoid resonance which causes vibration failure. So that fan can run safely in operating conditions.

In the contours of total deformation and equivalent stress we can see the points where the maximum deformation is taking place and maximum stress acting. By studying these contours we can take preventive measures to avoid any premature failures. In the fatigue analysis the contours of fatigue life, fatigue damage and fatigue factor of safety are plotted. By studying these contours we can determine material life cycles, material damage on the fan and factor of safety of the fan structure in the operating conditions. By this study we can avoid the failures and further improvement in the design can be considered. In modal analysis the first ten natural frequencies of the centrifugal fan are compared to the frequency generated from fan operating speed. This is done to avoid resonance phenomenon which causes the vibration failure in the centrifugal fan.

\section{GEOMETRIC MODELLING AND MESHING OF CENTRIFUGAL FAN}

The modelling is done in Catia V5R20 software. This is because Catia V5R20 is modelling software and has sophisticated modelling tools that helped in modelling the complex geometries. Apart from the modelling tools the software has features that helped in creating cross-sections at different locations which helped in better visualization and understanding of the actual fan geometry. The dimensions of the various parts of the fan are given in the following 2-D drawings. From these 2-D drawings models can be generated in Catia software as the complete dimensions of the parts are given in these diagrams. 
International Journal of Recent advances in Mechanical Engineering (IJMECH) Vol.4, No.2, May 2015
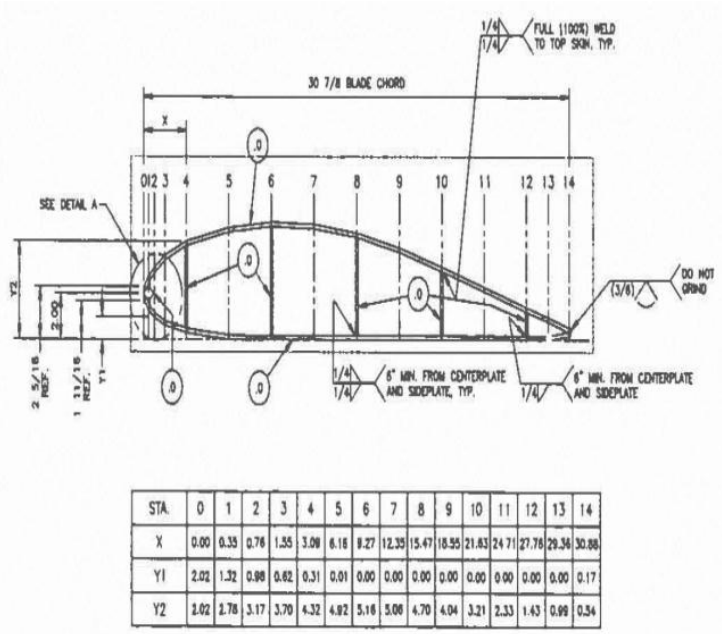

Fig. 2.1 2-D sectional view of aerofoil of centrifugal fan

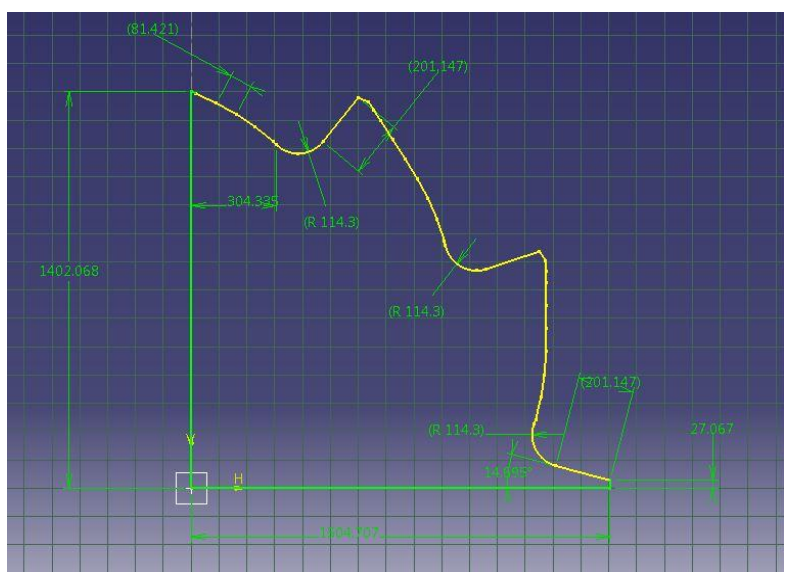

Fig. 2.2 2-D sectional view of an impeller of centrifugal fan

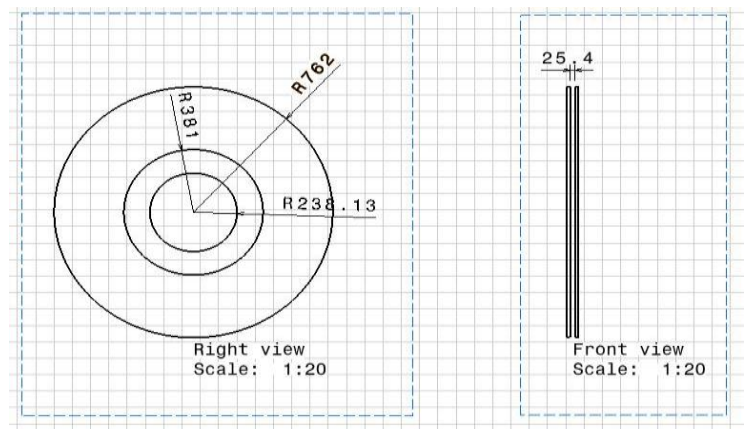

Fig. 2.3 2-D view of a clamping plate of a centrifugal fan

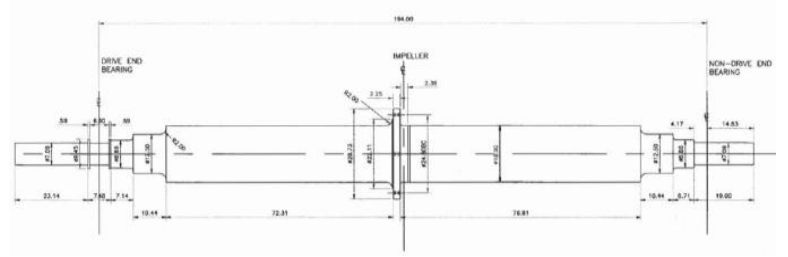

Fig. 2.4 2-D view of a shaft of a centrifugal fan 
International Journal of Recent advances in Mechanical Engineering (IJMECH) Vol.4, No.2, May 2015

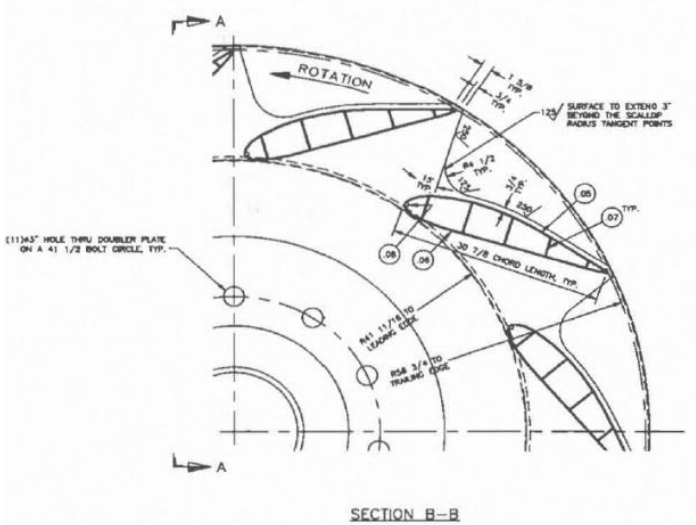

Fig. 2.5 2-D view of mounting of aerofoil on the impeller of a centrifugal fan

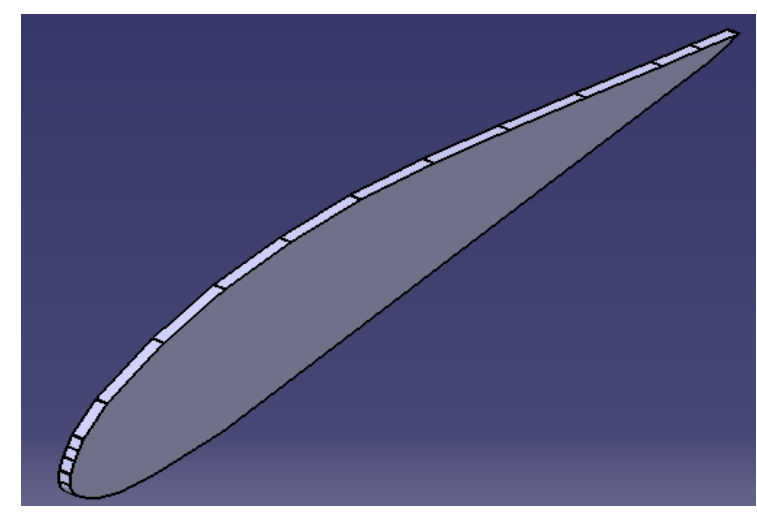

Fig. 2.6 CAD model of aerofoil of centrifugal fan

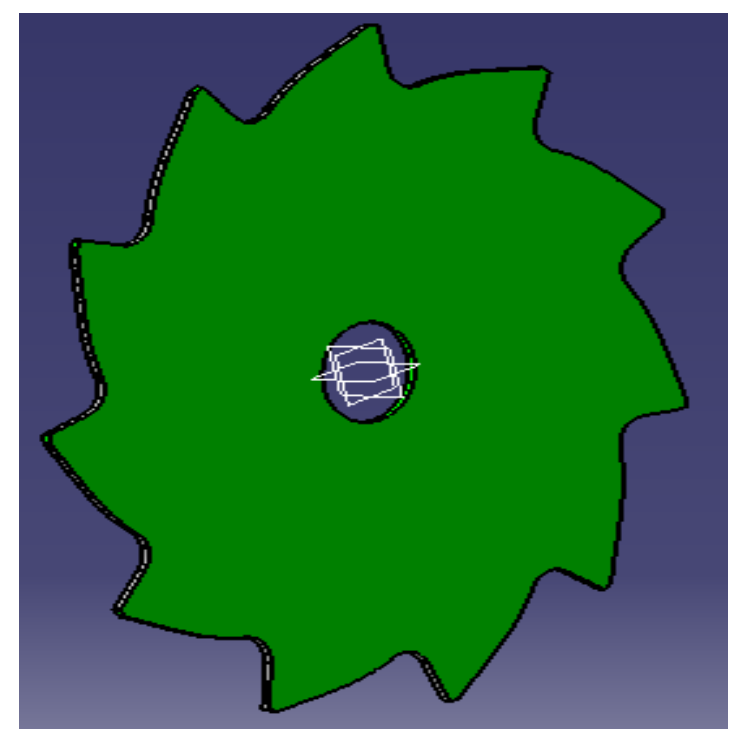

Fig. 2.7 CAD model of an impeller of centrifugal fan 
International Journal of Recent advances in Mechanical Engineering (IJMECH) Vol.4, No.2, May 2015

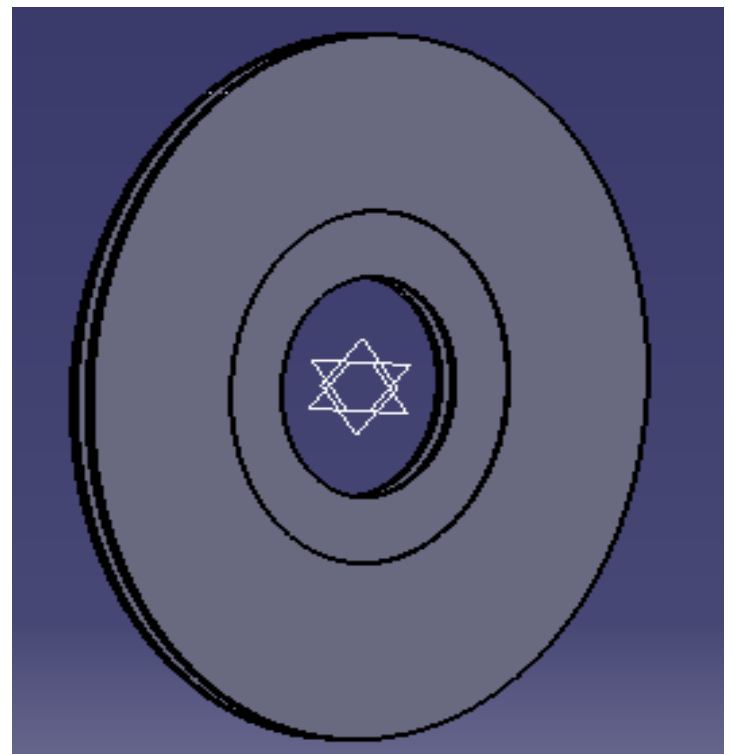

Fig. 2.8 CAD model of a clamping plate of a centrifugal fan

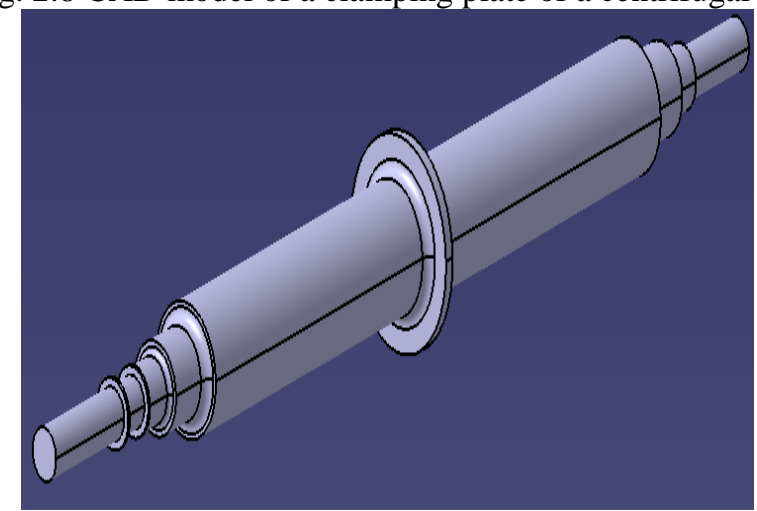

Fig. 2.9 CAD model of a shaft of a centrifugal fan

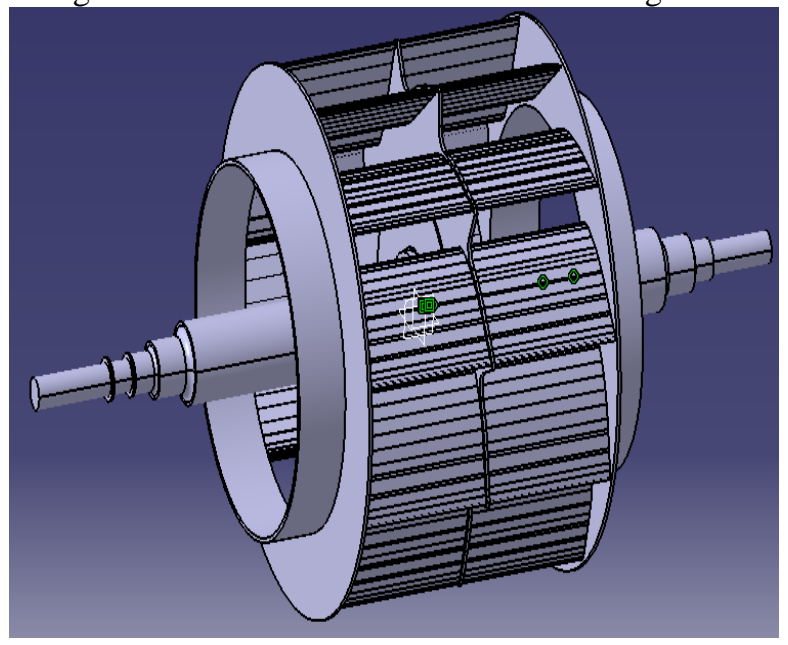

Fig. 2.10 Final assembled CAD model of a centrifugal fan used for analysis

Final assembly consists of a shaft, twenty two aerofoils, an impeller, two clamping plates and two supporting plates. 
Meshing of the centrifugal fan assembly is done by using ANSYS 12. Meshing of the pump consist of tetrahedral elements. Meshing consists of following numeric values:

Number of elements $=129842$

Number of nodes $=226376$

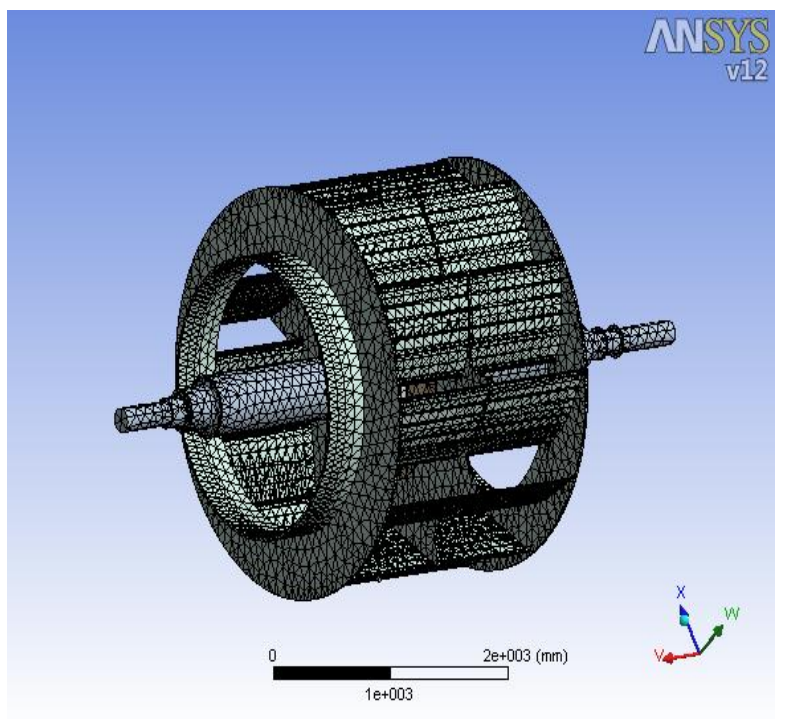

Fig. 2.11 Meshing of fan assembly (tetrahedral elements)

\section{COMPUTATIONAL EVALUATION OF FAN PERFORMANCE (FEA SIMULATION)}

Structural (FEA) analysis is done by using ANSYS 12 software. Structural analysis includes the fatigue testing of the fan. The fatigue testing on the fan is done at 705 RPM. In structural analysis contours of total deformation and equivalent stress is plotted using software. Contours of fatigue life, damage and safety factor are plotted using software. The material of the fan is structural steel. Volume and mass of the fan are $1.45 \times 10^{9} \mathrm{~mm}^{3}$ and $11413 \mathrm{~kg}$.

\subsection{Solution parameters}

- Number of RPM is constant that is 705 and temperature is $110^{\circ} \mathrm{F}$.

- Linear analysis is done.

- Static structure analysis is done.

- The model taken is Gerber mean stress theory for fatigue analysis.

- High cycle fatigue analysis with $10^{6}$ cycle is done.

- Constant amplitude fully reversed load is applied. 


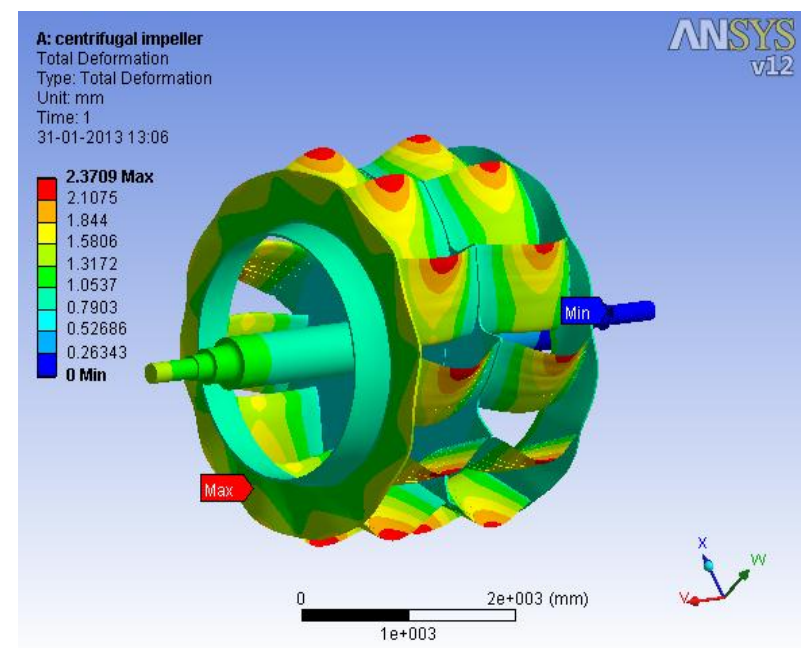

Fig. 3.1 Total deformation of fan at 705 RPM

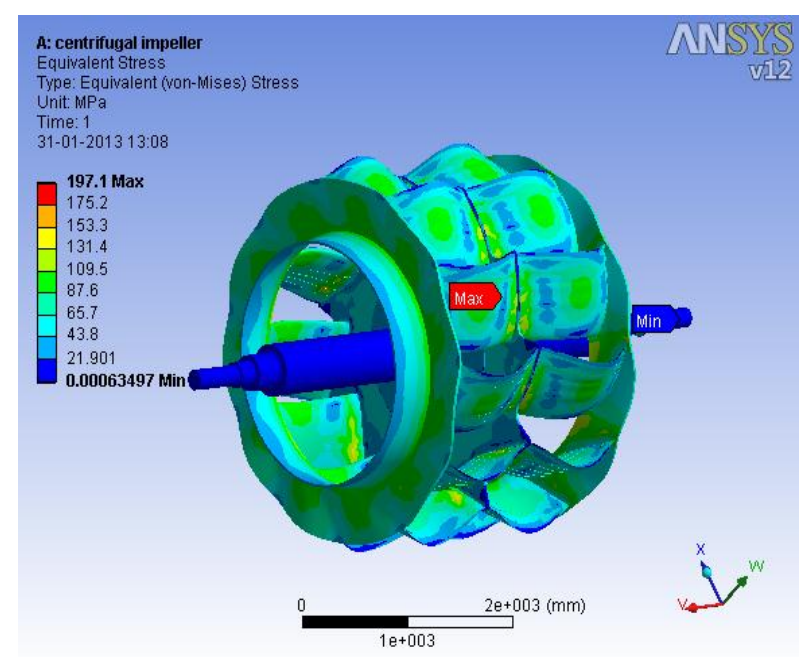

Fig. 3.2 Equivalent stress of fan at 705 RPM

Fig. 3.1 shows total deformation of fan at 705 RPM. Variation in the deformation is seen on the coloured bar. It is seen that maximum deformation takes place at the edges of the aerofoil which is shown by red colour. The deformation in the present case is very less in $\mathrm{mm}$ as shown in the figure. Fig. 3.2 shows equivalent stress on the fan. Variation in the equivalent stress is seen on the coloured bar. It is seen that maximum equivalent stress is acting at the aerofoil and contact points which is shown by green and yellow colours which means that if damage takes place it will start from contact points of the aerofoil.

\subsection{Fatigue analysis}

In the fatigue analysis of the fan three fatigue contours are plotted. The three plotted contours are fatigue life, fatigue damage and fatigue factor of safety. The three contours are shown below: 


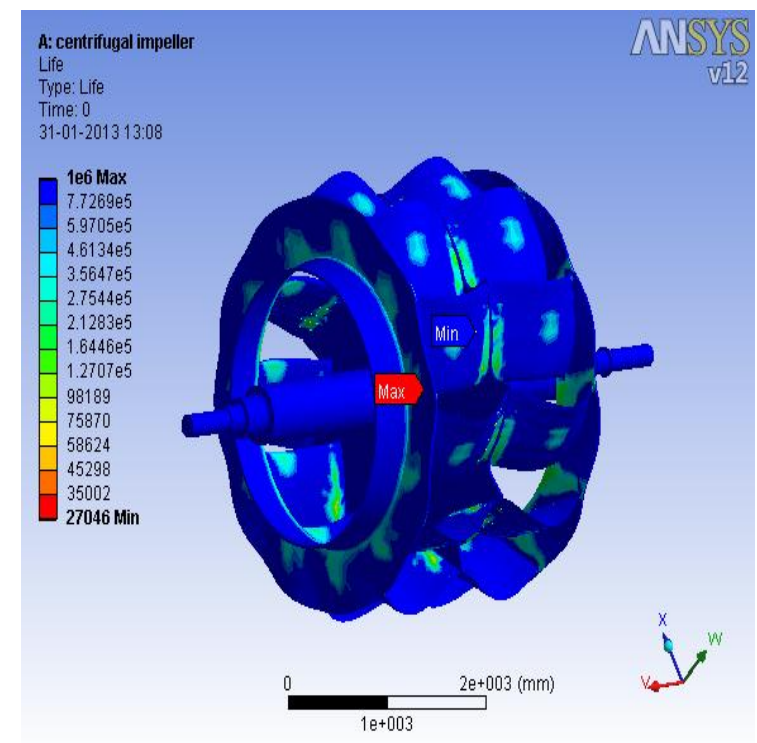

Fig. 3.3 Fatigue life of fan at 705 RPM

Fig. 3.3 shows the fatigue life contour of the fan. The figure shows the results from life represents the number of life cycles with the structure can withstand until it will fail due to fatigue. So from the above plot we can see that there is variation in coloured bar. Light blue colour at the contact of aerofoil and impeller shows that the structure will fail at these points before $10^{6}$ cycles and dark blue color shows that the structure will withstand up till $10^{6}$ cycles without any failure.

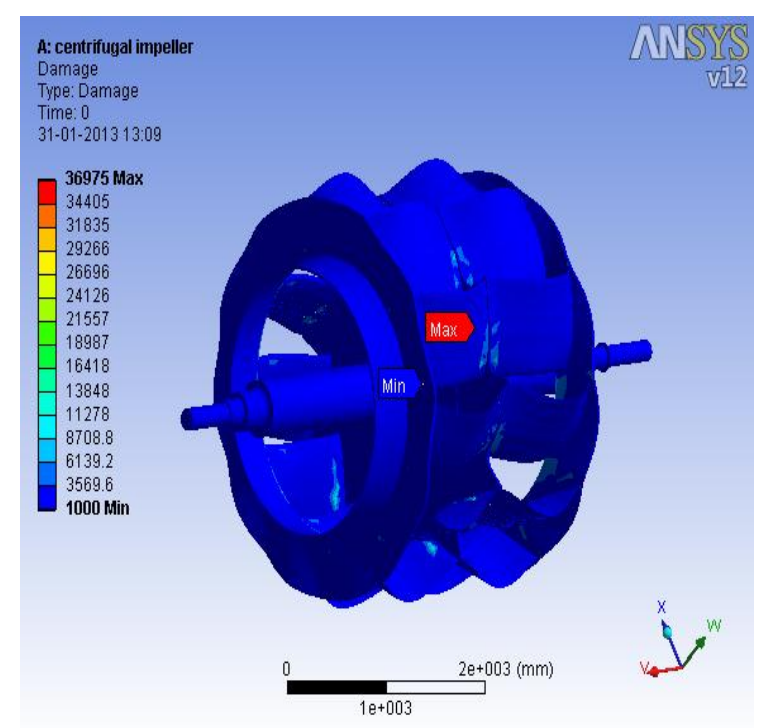

Fig. 3.4 Fatigue damage of fan at 705 RPM

Fig. 3.4 shows the fatigue damage of fan. It is seen that there is variation in the coloured bar showing damage in the fan. From the figure it is seen that damage occurs at the contact points of aerofoil and impeller. 


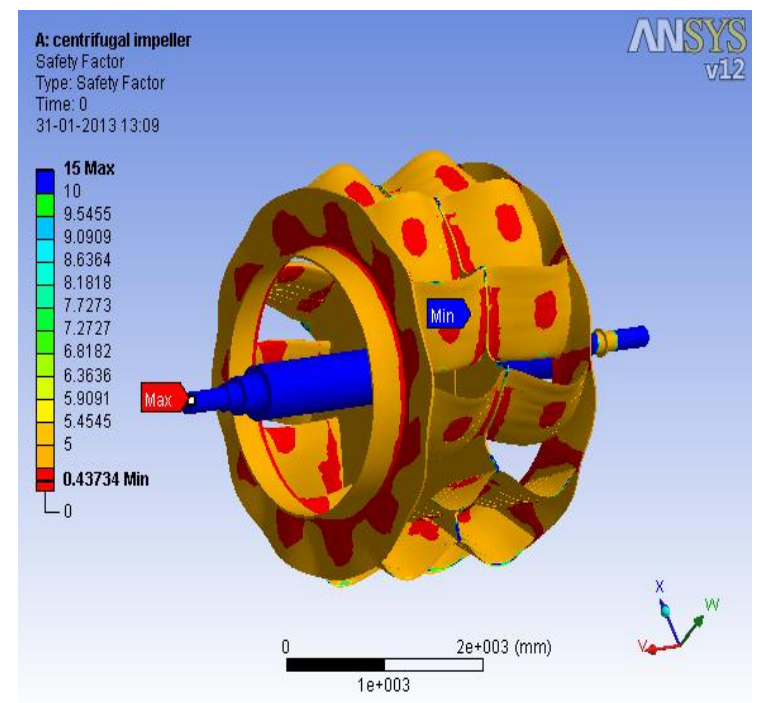

Fig. 3.5 Fatigue safety factor of fan at 705 RPM

Fig. 3.5 shows fatigue safety factor contour plot at a given design life cycle $\left(10^{6}\right)$. For fatigue safety factor, values less than one indicate failure before the design life is reached. In present case there are some region below one indicated by red color on the aerofoil and contact points. These points show the failure before the designed life. The structure is not safe to use under the operating condition without any failure in the structure.

From the results of the structure (FEA) analysis it is observed that in the deformation and equivalent stress contours there are some points in the fan structure where the damage occurs under the operating conditions. In order to avoid damage in the fan structure certain changes have to be done in the structure geometry and operating conditions.

From the contour of fatigue life it is observed that structure will fail or there would certain damage to the structure before the design life of $10^{6}$ cycles. In fatigue damage contour certain damage points is observed and in fatigue safety factor contour certain points are there whose safety factor is less than one which can fail under the operating conditions. In order to avoid failure in the fan structure before the designed life certain changes have to be done in the structure geometry and operating conditions.

\section{MODAL ANALYSIS OF PUMP IMPELLER}

Modal analysis is used to determine the vibration characteristics of as structure or a machine component while it is being designed. The machine may be rotating or non-rotating. Use of modal analysis is to determine the natural frequencies and mode shape of the structures and both these factor are very important design parameters. Vibration problems are most commonly associated with centrifugal fans. To ensure the safety of the fan and associated components, the vibration and noise must be kept within certain limits. Typical reasons for fan failures can be diagnosed well in advance by applying the right kind of vibration testing analysis. In the present work the modal analysis carried out for the centrifugal fan.

Firstly the frequency due the fan operating speed is calculated. Then this operating speed frequency is compared with fan natural frequencies at ten different modes. 
In this analysis it is being checked that fan operating speed frequency doesn't match with fan natural frequency to avoid resonance phenomena which causes the vibration failure to the fan and better performance of the fan in the operating conditions.

Since the fan is running at $705 \mathrm{RPM}$. So the frequency generated due to this speed is:

$$
f=\frac{N}{60}=\frac{705}{60}
$$

So

$$
f=11.75 \mathrm{~Hz}
$$

Now from the ANSYS 12 software the ten natural frequencies are being detected whose diagrammatic views are mentioned below:

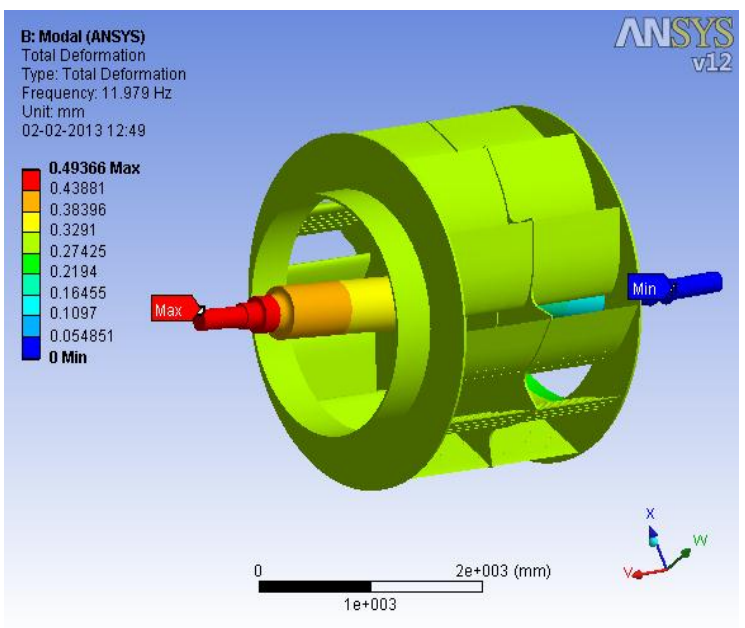

Fig. 4.1 Shape of the fan at natural frequency of $11.979 \mathrm{~Hz}$

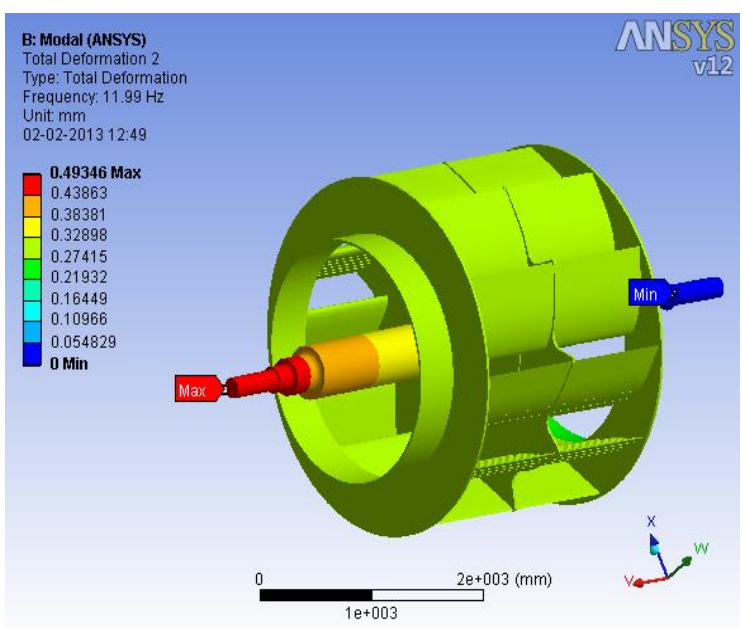

Fig. 4.2 Shape of the fan at natural frequency of $11.990 \mathrm{~Hz}$ 
International Journal of Recent advances in Mechanical Engineering (IJMECH) Vol.4, No.2, May 2015

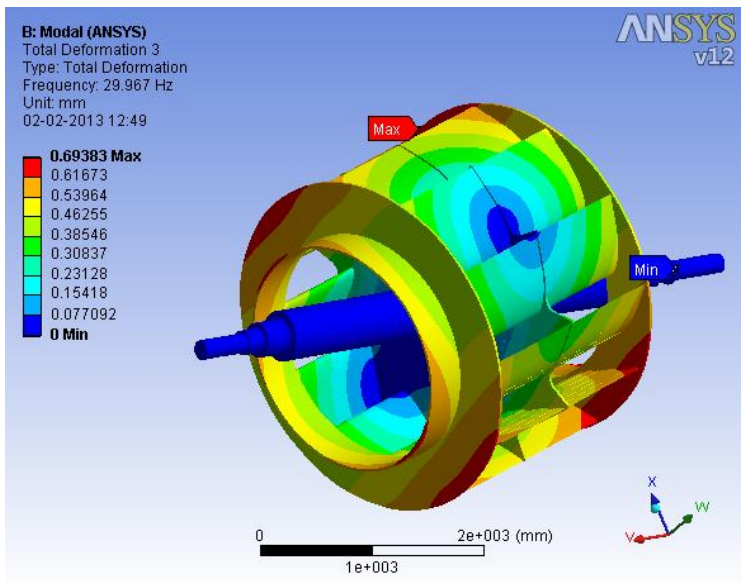

Fig. 4.3 Shape of the fan at natural frequency of $29.967 \mathrm{~Hz}$

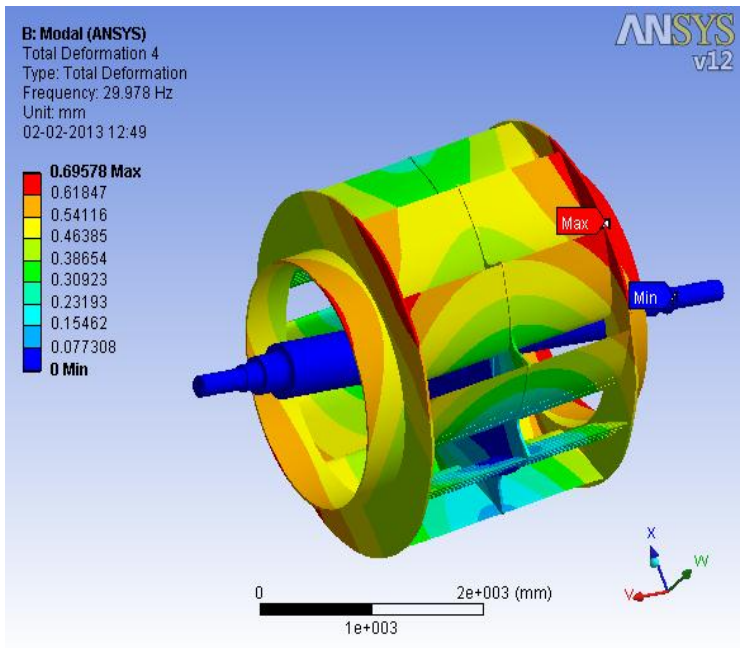

Fig. 4.4 Shape of the fan at natural frequency of $29.978 \mathrm{~Hz}$

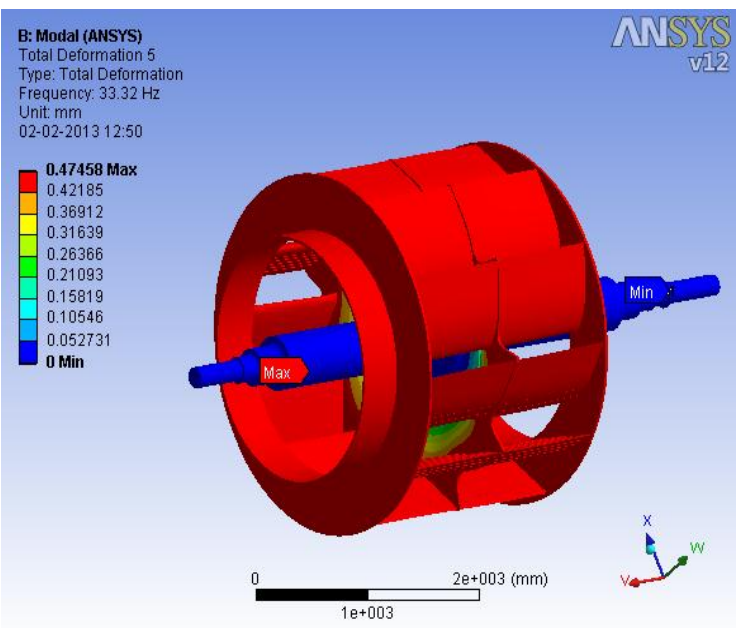

Fig. 4.5 Shape of the fan at natural frequency of $33.320 \mathrm{~Hz}$ 
International Journal of Recent advances in Mechanical Engineering (IJMECH) Vol.4, No.2, May 2015

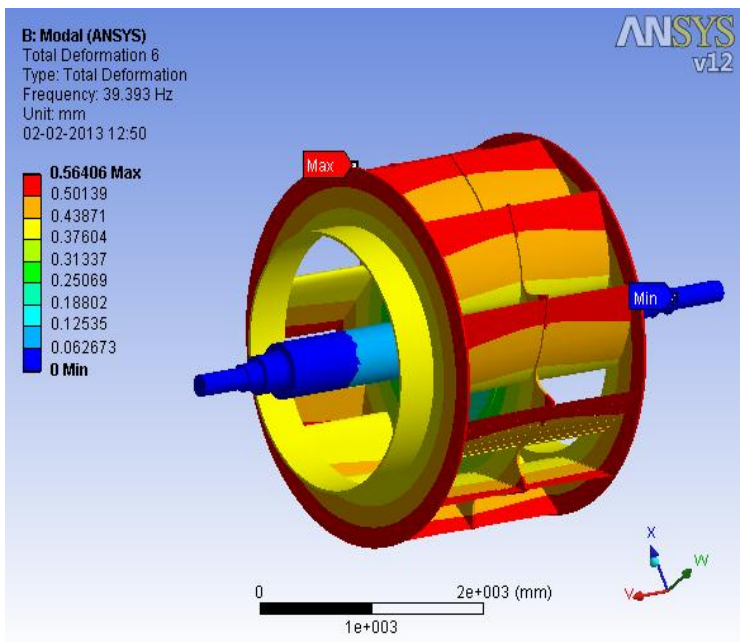

Fig. 4.6 Shape of the fan at natural frequency of $39.393 \mathrm{~Hz}$

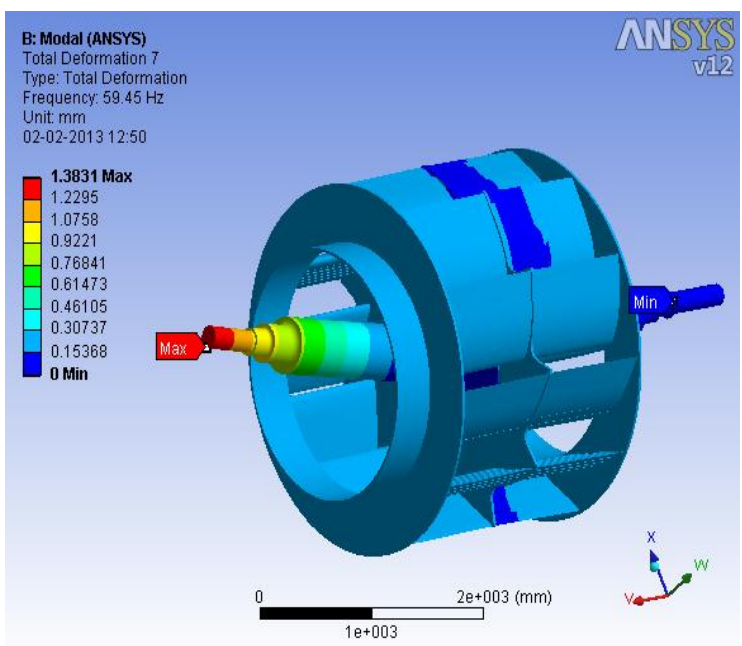

Fig. 4.7 Shape of the fan at natural frequency of $59.450 \mathrm{~Hz}$

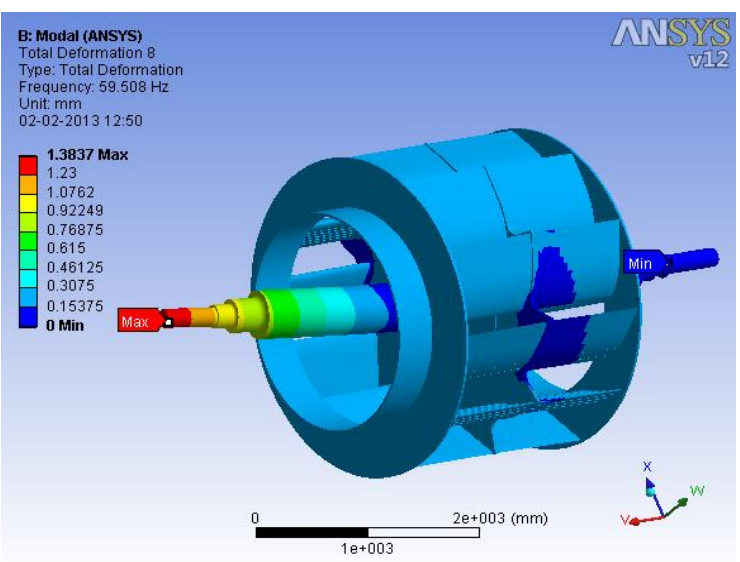

Fig. 4.8 Shape of the fan at natural frequency of $59.508 \mathrm{~Hz}$ 
International Journal of Recent advances in Mechanical Engineering (IJMECH) Vol.4, No.2, May 2015

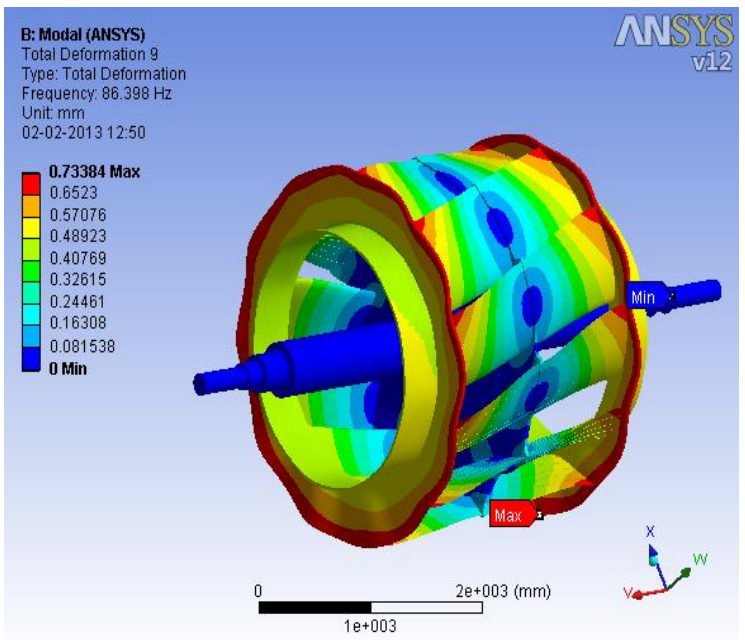

Fig. 4.9 Shape of the fan at natural frequency of $86.398 \mathrm{~Hz}$

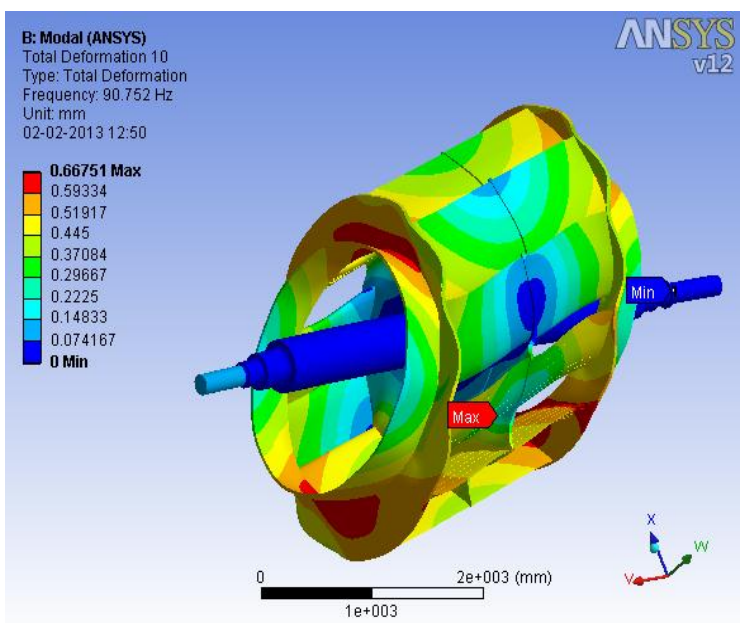

Fig. 4.10 Shape of the fan at natural frequency of $90.752 \mathrm{~Hz}$

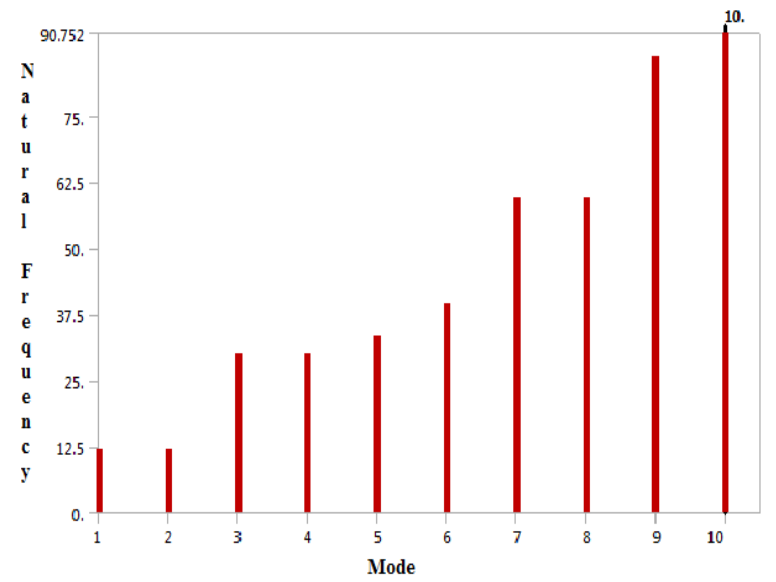

Fig. 4.11 Variation of the natural frequency of the fan with the changing modes 
Table 4.1 comparison of operating speed frequency $(\mathrm{Hz})$ and natural frequency $(\mathrm{Hz})$ of impeller of fan

\begin{tabular}{|c|c|c|}
\hline Mode & $\begin{array}{c}\text { Operating speed } \\
\text { frequency (Hz) }\end{array}$ & $\begin{array}{c}\text { Natural } \\
\text { frequency }(\mathbf{H z})\end{array}$ \\
\hline 1. & 11.75 & 11.979 \\
\hline 2. & 11.75 & 11.990 \\
\hline 3. & 11.75 & 29.967 \\
\hline 4. & 11.75 & 29.978 \\
\hline 5. & 11.75 & 33.320 \\
\hline 6. & 11.75 & 39.393 \\
\hline 7. & 11.75 & 59.450 \\
\hline 8. & 11.75 & 59.508 \\
\hline 9. & 11.75 & 86.398 \\
\hline 10. & 11.75 & 90.752 \\
\hline
\end{tabular}

From the above results calculated from the contour plots and mentioned in the table it was seen that operating speed frequency of the fan due to number of RPM doesn't match with the natural frequency of the fan at every mode. But there is only slight variation among the first two operating speed frequency and natural frequency. At these points resonance may occur due to which failure in the fan can occur. At rest other modes there is large variation among them at each and every mode. So from the above result it was concluded that resonance phenomena might occur at first two frequencies which can cause the vibration failure to the fan. If the operating speed frequency of the impeller matches with the natural frequency of the fan than the vibration failure occurs and high noise is being created. Vibration failure at different natural frequency at ten modes is shown in the contour plots. So at last from the above results we conclude that fan is not safe to run at first two frequencies. So some changes in the fan geometry and operating conditions have to be done for the safe functioning of the fan.

\section{CONCLUSION AND FUTURE WORK}

In this work, the geometry of fan is modelled and mesh is generated successfully. FEA is applied for the fatigue analysis of the fan. Contours of total deformation and equivalent stress are plotted. Modal analysis is done to determine the vibration characteristics of as structure or a machine component while it is being designed. Based on the model predictions of FEA and modal analysis the following conclusions are drawn:

- In the fatigue analyses of fan the contours of fatigue life, fatigue damage and fatigue safety factor were plotted and from the contours it is observed that fan will not run safely for its designed life i.e. $10^{6}$ cycles on the operating conditions. Some changes in design and operating conditions have to be done to avoid failure.

- From the fatigue damage contour it is observed that there is damage or distortion on the fan means that fan is not safe to run. From fatigue safety factor contour it is observed that there are some region below one indicated by red color on the aerofoil and contact points. These points show the failure before the designed life. The structure is not safe to use under the operating condition without any failure in the structure.

- In the FEA analysis certain contours of total deformation and equivalent stress acting on the fan. From the contours it is observed that the maximum deformation takes place at the edges of the aerofoil. The deformation in the present case is very less in $\mathrm{mm}$. It is seen that maximum equivalent stress is acting at the aerofoil and contact points which means that if damage takes place it will start from contact points of the aerofoil. 
- In the modal analysis it is observed operating speed frequency of the fan due to number of RPM doesn't match with the natural frequency of the fan at every mode. But there is only slight variation among the first two operating speed frequency and natural frequency. At these points resonance may occur due to which failure in the fan can occur. At rest other modes there is large variation among them at each and every mode. Some changes in design and operating conditions have to be done to avoid failure due to resonance.

With support of extensive results to validate the performance prediction of the FEA and Modal analysis, the obtained results from simulation of the numerical models can provide basis for longer-term objective of applying FEA as a design tool for investigating alternative measures necessary to ensure effective design and operation of centrifugal fan.

\subsection{Future Scope}

1. Flow analysis of the centrifugal fan can be done by using CFD simulation techniques.

2. In FEA analysis models like Goodman and Soderberg can be used for fatigue analysis.

3. FEA and modal analysis can also be done on other turbo machines like turbines, pump, compressors etc.

4. Spectrum analysis of the fan can be done.

\section{REFERENCES}

[1] I. Bucher and D. J. Ewins, "Modal Analysis and Testing of Rotating Structures", Philosophical Transactions: Mathematical, Physical and Engineering Sciences, vol. 359, No. 1778, pp. 61-96, 2001.

[2] Robert J. Sayer, "Finite Element Analysis - A Numerical Tool for Machinery Vibration Analysis", National Technical Training Symposium and 27th Annual Meeting of the Vibration Institute, New Orleans, pp. 18-21, July 2003.

[3] S.Ziaei Rad," Finite element, Modal testing and modal analysis of centrifugal pump impeller", Iranian Journal of Science and Technology, vol.29, pp. 157-169, 2005.

[4] Juan Gabriel Monge Gapper, "Centrifugal fan impeller failure analysis using finite elements", Ingeniería, ISSN: 1409-2441. San José, Costa Rica, pp. 55-62, January 2007.

[5] Binesh Philip and N. C. Mahendra Babu, "Numerical estimation of fatigue life of aero engine fan blades", SASTECH Journal, vol. 9, Issue 2, pp. 47-54, September 2010.

[6] Ramana Podugu, J.Suresh Kumar and B.V.Ramana murthy, "A modal approach for vibration analysis and condition monitoring of a centrifugal pump", International Journal of Engineering Science and Technology (IJEST), vol. 3, No. 8, pp. 6335-6344, August 2011.

[7] Mohammad Ranjbarkohan, Mohammad Reza Asadi, Masoud Mohammadi and Ahangari Heidar, "Fatigue Analysis of Connecting Rod of Samand Engine by Finite Element Method", Australian Journal of Basic and Applied Sciences, vol. 5, Issue 11, pp. 841-845, September 2011.

[8] L. Subramaniam and S. Sendilvelan, "Modal Analysis of a Centrifugal Pump Impeller", European Journal of Scientific Research, vol.79, No.1, pp.5-14, 2012.

[9] Robert J. Sayer, "Structural dynamics of centrifugal fans", Applied Structural Dynamics Medina, Ohio.

[10] ANSYS 12 Users guide and help. 